\title{
Yeast-enhanced green fluorescent protein (yEGFP): a reporter of gene expression in Candida albicans
}

\author{
Brendan P. Cormack, ${ }^{1}$ Gwyneth Bertram, ${ }^{2}$ Mark Egerton, ${ }^{3}$ \\ Neil A. R. Gow, ${ }^{2}$ Stanley Falkow ${ }^{1,4}$ and Alistair J. P. Brown ${ }^{2}$
}

Author for correspondence: Brendan P. Cormack. e-mail : cormack@cmgm.stanford.edu (European requests for plasmid to Alistair J. P. Brown, e-mail: al.brown@abdn.ac.uk; all other requests to Brendan P. Cormack)

\author{
1 Department of \\ Microbiology and \\ Immunology, Stanford \\ University School of \\ Medicine, Stanford, CA \\ 94305-5402, USA \\ 2 Molecular and Cell \\ Biology, University of \\ Aberdeen, Institute of \\ Medical Sciences, \\ Foresterhill, Aberdeen \\ AB25 2ZD, UK \\ 3 Zeneca Pharmaceuticals, \\ Alderley Park, Macclesfield \\ SK10 4TG, UK \\ 4 Rocky Mountain \\ Laboratories, National \\ Institute of Allergy and \\ Infectious Diseases, \\ Hamilton, MT 59840, USA
}

\begin{abstract}
The green fluorescent protein (GFP) of Aequorea victoria has been developed here as a reporter for gene expression and protein localization in Candida albicans. When wild-type (wt) GFP was expressed in C. albicans, it was not possible to detect fluorescence or a translation product for the wt protein. Since this was probably due in part to the presence of the non-canonical CTG serine codon in the Aequorea sequence, this codon was changed to the leucine codon TTG. C. albicans cells expressing this construct contained GFP mRNA but were non-fluorescent and contained no detectable translation product. Hence a codon-optimized GFP gene was constructed in which all of the 239 amino acids are encoded by optimal codons for $C$. albicans. In this gene were also incorporated two previously identified mutations in the chromophore that increase GFP fluorescence. C. albicans cells expressing this yeast-enhanced GFP gene (yEGFP3) are fluorescent and contain GFP protein. yEGFP3 can be used as a versatile reporter of gene expression in $C$. albicans and Saccharomyces cerevisiae and the optimized GFP described here should have broad applications in these and other fungal species.
\end{abstract}

Keywords: enhanced GFP, green fluorescent protein, Candida albicans, Saccharomyces cerevisiae

\section{INTRODUCTION}

Candida albicans, an important human pathogen (Cutler, 1991; Odds, 1988, 1994), has no known sexual cycle. In addition, because it is diploid (Scherer \& Magee, 1990), classical genetic analyses have been very difficult. Most genetic analyses have relied on 'reverse genetics', involving gene cloning and targeted gene disruption followed by phenotypic analysis. Furthermore, it has proven difficult to functionally express proteins from other species in C. albicans, and as a result, until recently there has been no reporter system for $C$. albicans. This difficulty in heterologous protein expression has been generally ascribed to the presence in C. albicans (and some other related species) of a noncanonical genetic code, in which CTG codons are

Abbreviations: FACS, fluorescence-activated cell sorting; GFP, green fluorescent protein; wt, wild-type.

The GenBank accession number for the yEGFP3 sequence is U73901. decoded as serine instead of leucine (Ohama et al., 1993; Santos et al., 1994; Santos \& Tuite, 1995; White et al., 1995). Recently, the C. albicans URA3 gene (Brown et al., 1996; Myers et al., 1995), the LAC4 gene of Kluyveromyces lactis (Leuker et al., 1992) and the Renilla reniformis luciferase which contains no CTG codons (Srikantha et al., 1996) have been developed as reporters of gene transcription.

We were interested in using the green fluorescent protein (GFP) of the jellyfish Aequorea victoria as a marker for gene expression and protein localization in C. albicans. GFP absorbs light with an excitation maximum of $395 \mathrm{~nm}$, and fluoresces with an emission maximum of $510 \mathrm{~nm}$ (Morise et al., 1974; Ward et al., 1980). Since this can occur in the absence of any cofactors, GFP has been extremely useful as a marker for gene expression and as a tag in studying protein localization in a variety of organisms (Chalfie et al., 1994; Cubitt et al., 1995; Sidorova et al., 1995; Wang \& Hazelrigg, 1994). However, the Aequorea GFP sequence contains a single CTG codon, potentially precluding its use in Candida. 
It is shown here that neither the wild-type (wt) GFP gene, nor a mutated GFP gene in which the CTG codon has been changed to TTG, is expressed in C. albicans. However, a synthetic GFP gene that carries optimal codons for translation in C. albicans, as well as two chromophore mutations that increase GFP fluorescence (Cormack et al., 1996), is functional in C. albicans. This yeast-enhanced GFP (yEGFP3) is evaluated here as an efficient reporter of gene expression in Saccharomyces cerevisiae as well as C. albicans, and as a reporter in the context of infected host tissue.

\section{METHODS}

Strain maintenance. The C. albicans strain CAI4 (ura3s::imm434/ura3s::imm434) (Fonzi \& Irwin, 1993) is a ura3 $^{-}$derivative of $\mathrm{Ca} 5314$ and was a gift from Bill Fonzi (Georgetown University Medical Center, Washington, DC, USA). CAI4 was grown in YPD ( $1 \%, \mathrm{w} / \mathrm{v}$, yeast extract; $2 \%$, $\mathrm{w} / \mathrm{v}$, peptone; $2 \%, \mathrm{w} / \mathrm{v}$, dextrose) supplemented with $25 \mathrm{mg}$ uridine $\mathrm{l}^{-1}$. The $S$. cerevisiae strain W303-1B (MATa ade 2 his 3 leu2 trp1 ura3) (Thomas \& Rothstein, 1989) was propagated on YPD agar. C. albicans and $S$. cerevisiae were grown in synthetic media $(2 \%, \mathrm{w} / \mathrm{v}$, glucose, galactose or maltose; $0.65 \%$ Yeast Nitrogen Base without amino acids; and the appropriate supplements at $50 \mathrm{mg} \mathrm{l}^{-1}$; Guthrie \& Fink, 1991) at $30^{\circ} \mathrm{C}$ with shaking at 200 r.p.m., and harvested during exponential growth $\left(\mathrm{OD}_{600} 0.8\right)$ for RNA and protein analyses.

Yeast transformation. Transformation for $S$. cerevisiae was as previously described by Gietz et al. (1992) and Ito et al. (1983). C. albicans was transformed by the protoplasting method of Kurtz et al. (1986), or using a modification of the S. cerevisiae protocol. Cells were grown in YPD to early-exponential phase, and collected by centrifugation $(1000 \mathrm{~g}, 5 \mathrm{~min})$. They were washed twice with water, and resuspended in $0 \cdot 1 \mathrm{M}$ LiAc, $1 \mathrm{mM}$ EDTA and $10 \mathrm{mM}$ Tris $/ \mathrm{HCl}$ (pH 7.5). To the cells were added $10 \mu \mathrm{g}$ transforming DNA with $100 \mu \mathrm{g}$ denatured salmon sperm DNA and $0.5 \mathrm{ml} 0.1 \mathrm{M} \mathrm{LiAc,} 40 \%$ (w/v) PEG (3350), $1 \mathrm{mM}$ EDTA and $10 \mathrm{mM}$ Tris $/ \mathrm{HCl}$ $\left(\mathrm{pH} \mathrm{7.5)}\right.$. The mix was incubated at $30^{\circ} \mathrm{C}$ for $30 \mathrm{~min}$, and heat-shocked at $45^{\circ} \mathrm{C}$ for $15 \mathrm{~min}$. The cells were collected by centrifugation $(1000 \mathrm{~g}, 5 \mathrm{~min})$ and plated on synthetic medium lacking uridine.

Construction of the codon-optimized yEGFP genes. The nomenclature for the codon-optimized GFP molecules follows that previously published (Cormack et al., 1996). Thus, the chromophore mutations in GFPmut1, GFPmut2 and GFPmut3 (Cormack et al., 1996) are present in the yeast-optimized genes yEGFP1, yEGFP2 and yEGFP3, respectively. The yEGFP3 gene was constructed in three parts using nine oligonucleotides. The sequences of the oligonucleotides are given in Table 1.

Oligonucleotides A1-3, B1-3 and C1-3 were used in three PCR reactions to generate three fragments (Fig. 1). Fragment A was cloned into pUC19 after digestion with HindIII and EcoRI. Fragment B was blunt cloned into the vector pCRII (Invitrogen). Fragment C was cloned into pUC19 after digestion with EcoRI and PstI. All three fragments were sequenced to verify that there were no mutations introduced by the PCR. Subsequently, fragment A was digested with HindIII and NdeI, fragment $\mathrm{B}$ with $N d e \mathrm{I}$ and $H p a \mathrm{I}$ and fragment $\mathrm{C}$ with $H$ paI and $P s t \mathrm{I}$, and the three products were cloned in a quadruple ligation into pUC19 digested with HindIII and PstI. The resulting vector, pYGFP3, was designed such that the GFP was in-frame with the lacZ of pUC19, and therefore the final clone was highly fluorescent in E. coli.

For the construction of two additional GFP mutant genes, yEGFP1 and yEGFP2, we replaced the HindIII-NdeI fragment of pYGFP3 with HindIII-NdeI fragments obtained by PCR of pYGFP3 with the following oligonucleotides:

(1) 5' GGAATTCAAAGCTTTATTAAAATGTCTAAAGGTGAA

Table 1. Oligonucleotides used for constructing yEGFP3

Restriction sites used for cloning are in bold.

\begin{tabular}{|c|c|}
\hline Oligo & Sequence \\
\hline A1 & $\begin{array}{l}\text { GGGATCCAAAGCTTTATTAAAATGTCTAAAGGTGAAGAATTATTCACTGGTGTTGTCCCAATTTTGGTTG } \\
\text { AATTAGATGGTGATGTTAATGGTCACAAATTTTCTGTCTCC }\end{array}$ \\
\hline A2 & $\begin{array}{l}\text { AATGGTCACAAATTTTCTGTCTCCGGTGAAGGTGAAGGTGATGCTACTTACGGTAAATTGACCTTAAAAT } \\
\text { TTATTTGTACTACTGGTAAATTG }\end{array}$ \\
\hline A3 & $\begin{array}{l}\text { GGGAATTCCATATGATCTGGGTATCTAGCAAAACATTGAACACCATAACCGAAAGTAGTGACTAAGGTTG } \\
\text { GCCATGGAACTGGCAATTTACCAGTAGTACAAATAAA }\end{array}$ \\
\hline B1 & $\begin{array}{l}\text { GGGAATTCCCATATGAAACAACATGACTTTTTCAAGTCTGCCATGCCAGAAGGTTATGTTCAAGAAAGAAC } \\
\text { TATTTTTTTCAAAGATGACGGTAACTACAAGACCAGAGCTGAA }\end{array}$ \\
\hline B2 & $\begin{array}{l}\text { AACTACAAGACCAGAGCTGAAGTCAAGTTTGAAGGTGATACCTTAGTTAATAGAATCGAATTAAAAGGTA } \\
\text { TTGATTTTAAAGAAGATGGTAACATTTTAGGT }\end{array}$ \\
\hline B3 & $\begin{array}{l}\text { TCTAATTTTGAAGTTAACTTTGATACCATTCTTTTGTTTGTCAGCCATGATGTAAACATTGTGAGAGTTAT } \\
\text { AGTTGTATTCCAATTTGTGACCTAAAATGTTACCATCTTC }\end{array}$ \\
\hline $\mathrm{Cl}$ & $\begin{array}{l}\text { GACAGAATTCGTTAACTTCAAAATTAGACACAACATTGAAGATGGTTCTGTTCAATTAGCTGACCATTATC } \\
\text { AACAAAATACTCCAATTGGTGATGGTCCAGTCTTGTTACCA }\end{array}$ \\
\hline $\mathrm{C} 2$ & $\begin{array}{l}\text { GATGGTCCAGTCTTGTTACCAGACAACCATTACTTATCCACTCAATCTGCCTTATCCAAAGATCCAAACGA } \\
\text { AAAG }\end{array}$ \\
\hline $\mathrm{C} 3$ & $\begin{array}{l}\text { AAAAAACTGCAGTTATTTGTACAATTCATCCATACCATGGGTAATACCAGCAGCAGTAACAAATTCTAACA } \\
\text { AGACCATGTGGTCTCTCTTTTCGTTTGGATCTTTGGA }\end{array}$ \\
\hline
\end{tabular}




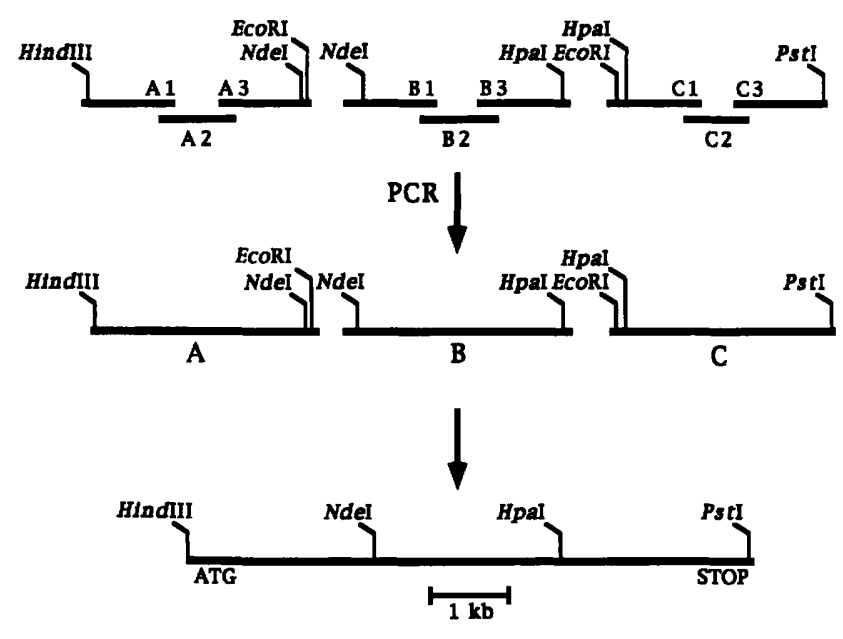

Fig. 1. Scheme for synthesis of the yEGFP3 gene, using C. albicans optimal codons.

(2) yEGFP1: GGGAATTCCATATGATCTGGGTATCTAGAAAAACATTGAACACCATAAGTTAAAGTAGTGGAC

\section{(3) yEGFP2: GGGAATTCCATATGATCTGGGTATCTA- GCAAAACATTGTAAACCATAAGCGAAAGTAGTGAC}

The restriction sites used for cloning are shown in bold. The plasmids corresponding to these mutant GFPs are pYGFP1 and pYGFP2.

A fourth GFP gene (GFP ${ }_{\text {TrG }}$ ) was made in which the single CTG codon was replaced with the optimal leucine codon, TTG. Oligonucleotides corresponding to the top and bottom strands of the wt GFP gene (GFP ${ }_{\mathrm{wt}}$ ) between the MunI and $B s t \mathrm{BI}$ sites were made with this CTG to TTG mutation. These oligonucleotides were annealed and cloned into gel-purified pGFP (Clontech) digested with MunI and BstBI. The GFP mutation was confirmed by DNA sequencing (Sanger et al., 1977).

Gene expression. Constitutive expression of the GFP genes in C. albicans and $S$. cerevisiae was achieved using pYPBADHpt. This expression vector contains a C. albicans autonomously replicating sequence, the $C$. albicans URA3 selectable marker, $S$. cerevisiae $2 \mu$ sequences, the $E$. coli ampicillin-resistance gene and the C.albicans $A D H 1$ promoter and terminator regions (Bertram et al., 1996) separated by unique EcoRV, BglII, XhoI and StuI sites (G. Bertram, I. D. Broadbent, P. J. F. Feldmann \& A. J. P. Brown, unpublished). The $\mathrm{GFP}_{\mathrm{wt}}$ and $\mathrm{GFP}_{\mathrm{TTG}}$ genes were PCR-amplified using primers that introduced $5^{\prime}$-BglII and $3^{\prime}$-X XoI sites, and cloned between the BglII and $3^{\prime}$-XhoI sites in pYPB-ADHpt. yEGFP3 (the HindIII-PstI fragment from pYGFP3) was blunted using the Klenow fragment of DNA polymerase I and inserted into the EcoRV site of pYPB-ADHpt.

yEGFP3 was expressed inducibly in C. albicans using pRC2312MAL. This vector was constructed as follows. The C. albicans MAL2 (Geber et al., 1992) promoter $(-540$ to the ATG) was amplified by PCR using the primers:

M1: GAACGCATGCGTCGACGATATTTTTGTCTAGTACCATC

M2: GAACTCTAGATGTAGTTGATTATTAGTTAAACC
This promoter was cloned as a SphI-XbaI fragment; the restriction sites are in bold. The $3^{\prime}$ untranslated region (including $256 \mathrm{bp} 3^{\prime}$ to the stop codon) of the MAL2 gene was amplified using the oligonucleotides:

M3: GAAAGGATCCATACGCTTTGCAGGTGGTGTTGATCCAAATTCC

M4: CTTCTCTAGAGAGCTCAGAGGAATTCGATTAAATATACACTAGATGCTATC

This was cloned as a BamHI-XbaI fragment; restriction sites are shown in bold. The $5^{\prime}$ and $3^{\prime}$ regions of the MAL2 gene were combined into the high-copy-number vector pRC2312 (Cannon et al., 1992), digested with HindIII and BamHI. This vector, p2312MAL, now contained the $5^{\prime}$ and $3^{\prime}$ untranslated regions of the MAL2 promoter flanking a polylinker containing XbaI, SacI and EcoRI sites. yEGFP3 (the HindIII-PstI fragment from pYGFP3) was blunted into the $\mathrm{X} b a$ I site of p2312MAL.

yEGFP1-3 was expressed inducibly in S. cerevisiae using the $G A L 1,10$ vector $\mathrm{pTS} 210$. This vector, a gift from Tim Stearns (Department of Biological Sciences, Stanford University), is a YCp50-based vector with the GAL1,10 promoter and transcriptional terminator of the ACT1 gene. Between these two is a polylinker containing BamHI, HindIII and $\mathrm{XbaI}$ sites. The polylinker sequence is GGATCCGCAAGCTTGCTCTAGA. The three codon-optimized GFPs were first cloned as HindIIIPstI fragments into pUC19. From there, they were cloned as HindIII-XbaI fragments into PTS210, digested with HindIII and $\mathrm{XbaI}$. The GFP ${ }_{\mathrm{wt}}$ construct in pTS210 was made by Tim Stearns and is called pTS395. This construct has GFP $_{\mathrm{wt}}$ cloned into the XbaI site of pTS210.

Northern analysis. RNA was prepared from C. albicans and $S$. cerevisiae as described previously (Brown, 1994; Lindquist, 1981). Approximately equal amounts of total RNA were subjected to Northern analysis (Moore et al., 1991) using radiolabelled GFP probes prepared by random-priming purified restriction fragments (Feinberg \& Vogelstein, 1983). The insert from pGFP (Clontech) was used to detect the GFP ${ }_{w t}$ and $\mathrm{GFP}_{\text {TTG }}$ mRNAs, and the insert from pYGFP3 was used to detect the yEGFP3 mRNA. However, both probes crossreacted with the heterologous GFP genes.

Western analysis. Protein extracts (Hostetter et al., 1990) were analysed by $10 \%$ (w/v) SDS-PAGE (Laemmli, 1970), electroblotted onto nitrocellulose membranes, and GFP polypeptides were detected using an anti-GFP polyclonal antibody (Clontech). The secondary antibody was alkaline-phosphatase-conjugated mouse anti-rabbit IgG (Sigma).

Microscopy and fluorescence-activated cell sorting (FACS) analysis. GFP expression was visualized in yeast cells by epifluorescence microscopy, with fluorescein isothiocyanate $(485 / 510 \mathrm{~nm}$, excitation/emission) and tetramethylrhodamine isothiocyanate $(540 / 605 \mathrm{~nm}$, excitation/emission) filters. For growth in serum, C. albicans transformed with the ADH-yEGFP3 construct was grown in YPD plus $10 \%(v / v)$ foetal calf serum overnight to saturation. For tissue preparation from infected mice, mice were killed at $24 \mathrm{~h}$ postinfection, and the kidneys were recovered. These were embedded in OCT (Tissue-Tek, Milles), frozen on dry ice, and cryosectioned in $5-10 \mu \mathrm{m}$ sections. The sections were fixed in $4 \%(\mathrm{v} / \mathrm{v})$ paraformaldehyde and mounted in Vectashield (Vector Laboratories) with $0.5 \mathrm{mg}$ propidium iodide $\mathrm{ml}^{-1}$.

A FACStar (Becton Dickinson) instrument equipped with an argon laser emitting at $488 \mathrm{~nm}$ was used for FACS analysis. Fluorescence emission was read with a $515 / 40$ band pass filter. 
Fluorescence and forward scatter data were collected with logarithmic amplifiers. The mean fluorescence intensities were calculated using the CellQuest software.

\section{RESULTS}

\section{The CTG codon does not explain the lack of GFP expression in C. albicans}

Our initial objective was to use the wt GFP gene as a reporter in C. albicans. However, when this gene was

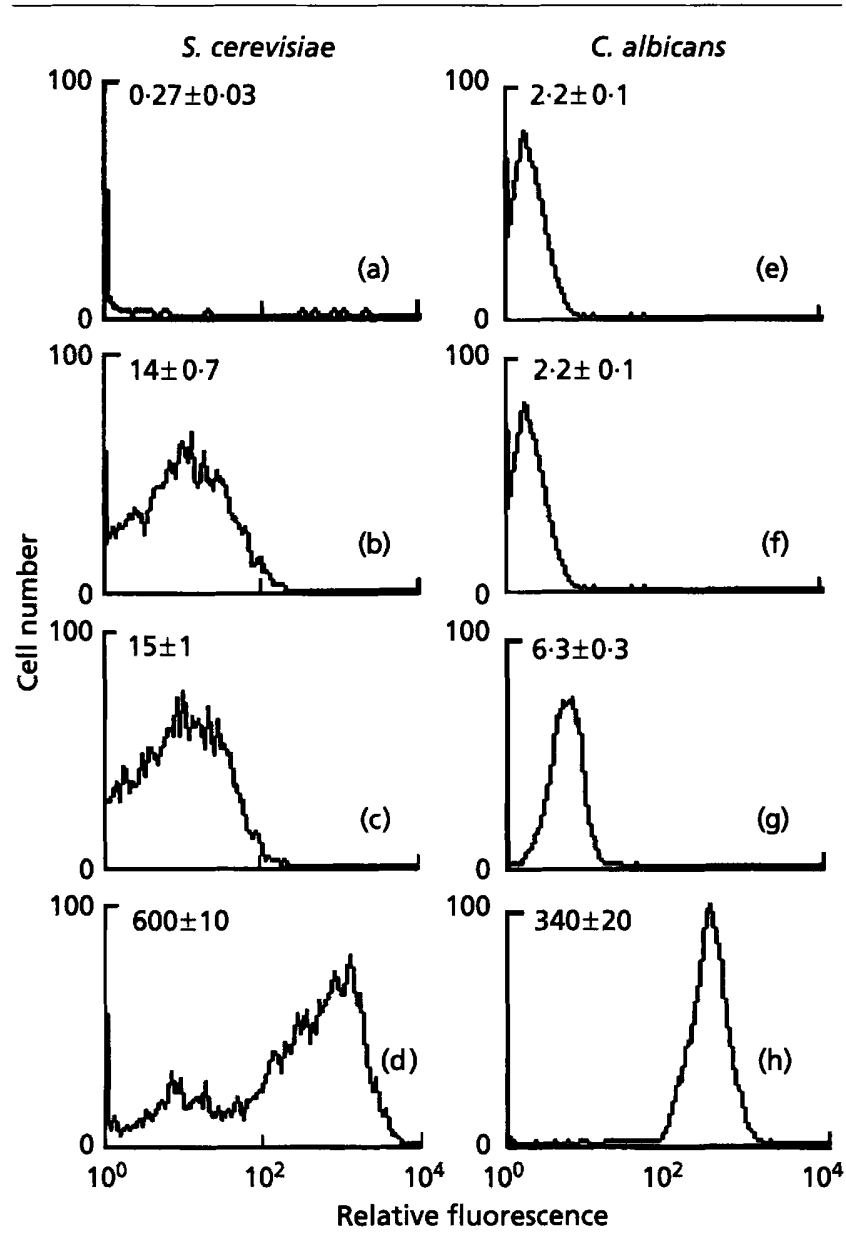

Fig. 2. FACS analysis of $S$. cerevisiae or $C$. albicans strains carrying various GFP constructs. Experiments were carried out on three independent transformants. The histograms shown are representative; the mean and standard deviations shown are calculated from the mean fluorescence for the three cultures. The vectors carried in each of the strains are as follows: $(a, e)$ pYPB-ADHpt; (b, f) pYPB-ADHpt-GFP ; (c, g) pYPB-ADHptGFP $_{\text {G }}$; (d, h) pYPB-ADHpt-yEGFP. Each histogram represents a total of $2 \times 10^{4}$ events. The mean fluorescence of each culture is shown in arbitrary units. The $S$. cerevisiae baseline (a) was set lower than that for $C$. albicans to permit comparison of fluorescence in $(a-c)$ with the extremely high fluorescence in (d). Thus direct comparisons of fluorescence should be made only within the $S$. cerevisiae and $C$. albicans groups. Since the histogram in (a) is offscale, a second set of measurements were taken for the cultures in (a) and (b), with the baseline set to allow accurate analysis of both histograms. The fluorescence value of 0.27 was calculated from the ratio of the values for cultures (a) and (b) in this set of measurements. cloned into the expression vector pYPB-ADHpt and transformed into $C$. albicans, no fluorescence was observed, although the same construct yielded high levels of fluorescence in $S$. cerevisiae (Fig. 2b, $\mathrm{f}$ ). The lack of expression in C. albicans might have been due to the translation of the single CTG codon in the $\mathrm{GFP}_{\mathrm{wt}}$ gene (Prasher et al., 1992) as serine rather than leucine (Santos \& Tuite, 1995). Hence, we changed codon 201 to the preferred leucine codon, TTG (Brown et al., 1991; Lloyd \& Sharp, 1992), and compared the expression of this $\mathrm{GFP}_{\mathrm{TTG}}$ gene in C. albicans and S. cerevisiae (Fig. $2 \mathrm{c}, \mathrm{g})$. High levels of fluorescence were observed in $S$. cerevisiae, but no fluorescence was seen in C. albicans. Therefore, the presence of a CTG codon in $\mathrm{GFP}_{\mathrm{wt}}$ is not sufficient to account for the lack of expression of this gene in C. albicans.

\section{Construction of codon-optimized GFP}

A codon-optimized GFP (see Methods and Fig. 1) was constructed in which all the codons are optimal for C. albicans. The codon usage for the starting and final genes is shown in Fig. 3. For the codon-optimized genes (yEGFP3), we were guided by a codon usage table derived from three highly expressed Candida genes: TEF3, ENO1 and HSP7O [assembled by S. Scherer (University of Minnesota School of Medicine, MN, USA) and available at http://alces.med.umn.edu/ candida/codons.html]. In addition to the codon usage changes in the optimized GFP gene, two amino acid changes relative to the wt gene (S65G; S72A) were included. GFP with this double amino acid change fluoresces 75 times more brightly than wt GFP when expressed in E. coli and excited at $488 \mathrm{~nm}$ (Cormack et al., 1996). The mutations shift the absorbance maxima from $395 \mathrm{~nm}$ to $490 \mathrm{~nm}$, and increase the solubility of the protein.

\begin{tabular}{|c|c|c|c|c|c|c|c|c|}
\hline $\begin{array}{l}\text { TTT Phe } 8 \\
\text { TTC Phe } 5 \\
\text { TTA Leu } \\
\text { TTG Leu }\end{array}$ & & $\begin{array}{l}8 \\
5 \\
12 \\
7\end{array}$ & $\begin{array}{l}\text { TCT Ser } 3 \\
\text { TCC Ser } 1 \\
\text { TCA Ser } 2 \\
\text { TCG Ser } 1\end{array}$ & $\begin{array}{l}6 \\
3 \\
- \\
-\end{array}$ & $\begin{array}{l}\text { TAT Tyr } 4 \\
\text { TAC Tyr } 7 \\
\text { TAA Stop } 1 \\
\text { TAG Stop- }\end{array}$ & $\begin{array}{l}4 \\
7 \\
1 \\
-\end{array}$ & $\begin{array}{l}\text { TGT Cys - } \\
\text { TGC Cys } 2 \\
\text { TGA Stop- } \\
\text { TGG Trp 1 }\end{array}$ & $\begin{array}{l}2 \\
- \\
-\end{array}$ \\
\hline $\begin{array}{l}\text { CTT Leu } \\
\text { CTC Leu - } \\
\text { CTA Leu } \\
\text { CTG Leu }\end{array}$ & & $\begin{array}{l}- \\
- \\
-\end{array}$ & $\begin{array}{l}\text { CCT Pro } 2 \\
\text { CCC Pro } 2 \\
\text { CCA Pro } 6 \\
\text { CCG Pro- }\end{array}$ & $\begin{array}{l}- \\
10 \\
-\end{array}$ & $\begin{array}{l}\text { CAT His } 5 \\
\text { CAC His } 5 \\
\text { CAA Gin } 6 \\
\text { CAG GIn } 2\end{array}$ & $\begin{array}{l}5 \\
5 \\
8 \\
-\end{array}$ & $\begin{array}{l}\text { CGT Arg } 1 \\
\text { CGC Arg - } \\
\text { CGA Arg - } \\
\text { CGG Arg - }\end{array}$ & - \\
\hline $\begin{array}{l}\text { ATT lle } \\
\text { ATC lle } \\
\text { ATA lle } \\
\text { ATG Met }\end{array}$ & $\begin{array}{l}8 \\
3 \\
1 \\
6\end{array}$ & $\begin{array}{l}9 \\
3 \\
- \\
6\end{array}$ & $\begin{array}{l}\text { ACT Thr } 7 \\
\text { ACC Thr } 2 \\
\text { ACA Thr } 6 \\
\text { ACG Thr- }\end{array}$ & $\begin{array}{l}10 \\
5 \\
- \\
-\end{array}$ & $\begin{array}{l}\text { AAT Asn } 5 \\
\text { AAC Asn } 8 \\
\text { AMA Lys } 15 \\
\text { AAG Lys } 5\end{array}$ & $\begin{array}{l}5 \\
8 \\
15 \\
5\end{array}$ & $\begin{array}{l}\text { AGT Ser } 3 \\
\text { AGC Ser } 1 \\
\text { AGA Arg } 5 \\
\text { AGG Arg - }\end{array}$ & $\begin{array}{l}- \\
6 \\
-\end{array}$ \\
\hline $\begin{array}{l}\text { GT Val } \\
\text { GTC Val } \\
\text { GTA Val } \\
\text { GTG Val }\end{array}$ & $\begin{array}{l}0 \\
6 \\
3 \\
-\end{array}$ & $\begin{array}{l}11 \\
6 \\
- \\
-\end{array}$ & $\begin{array}{l}\text { GCT Ala } 3 \\
\text { GCC Ala } 2 \\
\text { GCA Ala } 3 \\
\text { GCG Ala - }\end{array}$ & $\begin{array}{l}7 \\
2 \\
- \\
-\end{array}$ & $\begin{array}{ll}\text { GAT Asp } 12 \\
\text { GAC Asp } 6 \\
\text { GAA Glu } 13 \\
\text { GAG Glu } 3\end{array}$ & $\begin{array}{l}12 \\
6 \\
16 \\
-\end{array}$ & $\begin{array}{ll}\text { GGT Gly } & 7 \\
\text { GGC Gly } & 3 \\
\text { GGA Gly } & 9 \\
\text { GGG Gly } & 3\end{array}$ & $\begin{array}{l}23 \\
- \\
- \\
-\end{array}$ \\
\hline
\end{tabular}

Fig. 3. Codon usage tables for GFP. The first column in each set of two shows codon usage for the wt GFP gene from $A$. victoria. Codon usage for the optimized yEGFP is given in the second column. Note that in yEGFP there are two fewer serines and additional alanine and glycine residues relative to the original GFP sequence. This reflects the mutations in the chromophore that result in increased fluorescence. 

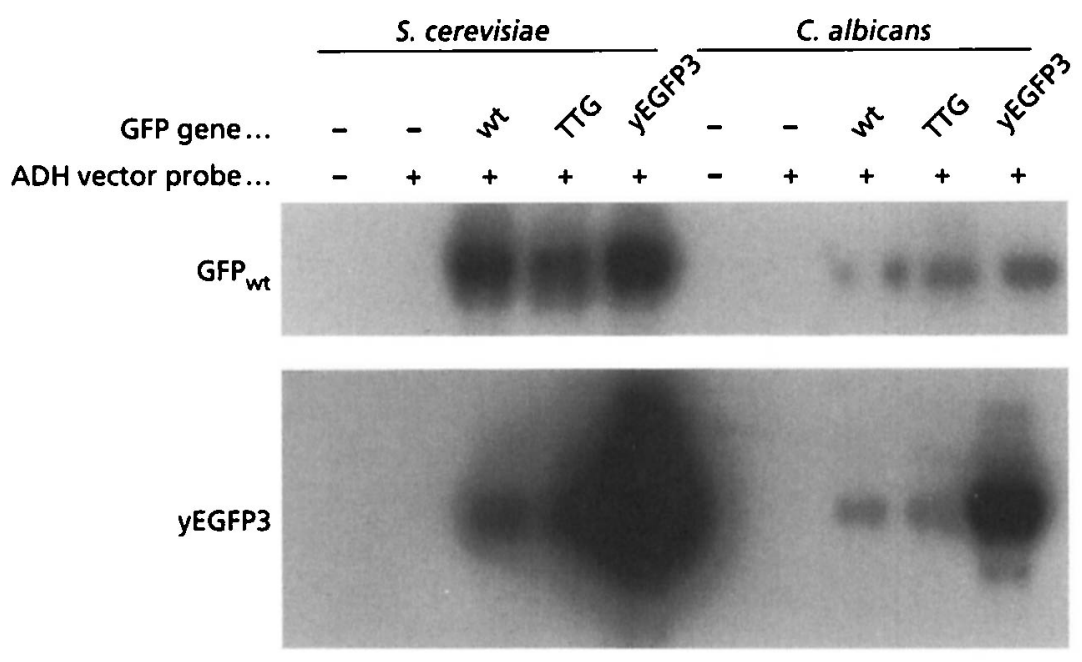

YEGFP3

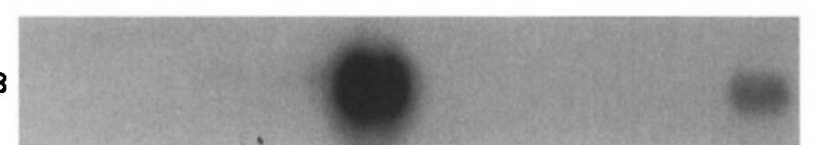

Anti-GFP

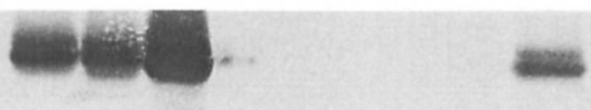

Fig. 4. GFP MRNA and protein levels in C. albicans and $S$. cerevisiae. RNA and protein extracts were prepared from exponential cultures of $C$. albicans and $S$. cerevisiae

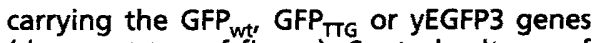
(shown at top of figure). Control cultures of untransformed cells, or cells transformed with the parent $A D H 1$ expression vector were also analysed. Northern analysis was performed on approximately equal amounts of RNA and the filters were probed with the GFP $_{\text {wt }}$ and yEGFP3 genes (shown at the side of figure). Two exposures of the same yEGFP3-probed filter are shown because of the high abundance of the yEGFP3 mRNA in $S$. cerevisiae. Western analysis was performed on approximately equal amounts of protein using an anti-GFP polyclonal antibody. The GFP band was calculated to be $24 \mathrm{kDa}$, in agreement with the prediction.

\section{The synthetic GFP gene generates fluorescence in $S$. cerevisiae and $C$. albicans}

The expression of the various GFP genes in S. cerevisiae and C. albicans was analysed by Northern and Western blotting (Fig. 4). In S. cerevisiae, no GFP transcript or protein was observed in untransformed cells or in cells transformed with the parent expression vector, whereas GFP transcript and protein was observed in cells transformed with vector containing each of the GFP genes. Not surprisingly, all $S$. cerevisiae transformants expressing GFP were fluorescent when illuminated at $488 \mathrm{~nm}$ (Fig. 2b-d). In C. albicans, Northern analysis revealed the presence of GFP mRNA in cells transformed with all ADH-GFP fusions (Fig. 4). However, Western analysis revealed GFP protein only in C. albicans strains containing the codon-optimized GFP gene; no protein could be detected in the negative controls, in cells transformed with the GFP wt $_{\text {, }}$ or even in cells transformed

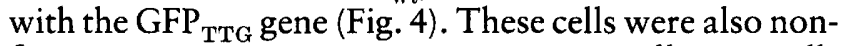
fluorescent (Fig. 2e-g). In contrast, C. albicans cells expressing yEGFP3 were highly fluorescent (Figs $2 \mathrm{~h}$ and 6a, b).

Comparing expression of GFP in $S$. cerevisiae and C. albicans, it was noticed that the levels of GFP mRNA were lower in C. albicans than in S. cerevisiae, consistent with a high copy number in $S$. cerevisiae due to the presence of $2 \mu$ sequences on the vector. Similar observations were made when pYPB-ADHpt was used to express the C. albicans sequences HST7 and HYR1 in S. cerevisiae and C. albicans (Bailey et al., 1996; Leberer et al., 1996). Interestingly, both in S. cerevisiae and C. albicans, the levels of the codon-optimized GFP mRNA were significantly higher than that for the $\mathrm{GFP}_{\mathrm{wt}}$ and
GFP $_{\text {TTG }}$ mRNAs. In both organisms, this correlated with elevated protein levels, and with elevated fluorescence.

\section{Inducible expression of yEGFP3}

To test if yEGFP3 could be used to measure promoter strength, it was placed under the control of the maltase promoter on the high-copy-number vector pRC2312MAL (see Methods). Two transformants were grown in synthetic medium containing glucose or synthetic medium containing maltose overnight to saturation. The fluorescence of the cultures was assessed by FACS analysis (Fig. 5a). While the cultures grown in glucose were virtually non-fluorescent, the cultures grown in maltose were 20 times more fluorescent. Different transformants of the pRC2312MAL-GFP did not behave identically. All transformants were more fluorescent in maltose than in glucose, but in some transformants, a substantial percentage of the cells remained non-fluorescent after induction (data not shown). It is not known if this was a result of plasmid loss, failure to induce the MAL2 promoter, or a failure of GFP to fluoresce in all cells. The latter explanation is less likely, since all cells fluoresce with virtually identical intensity when GFP is expressed from the constitutive $A D H 1$ promoter (Fig. $2 \mathrm{~h}$ ).

\section{yEGFP is highly fluorescent in S. cerevisiae}

The mean fluorescence for $S$. cerevisiae cells transformed with the ADH1-yEGFP3 construct was approximately $2 \times 10^{3}$ times greater than for the untransformed parental strain (Fig. 2d), and 40 times greater than for 

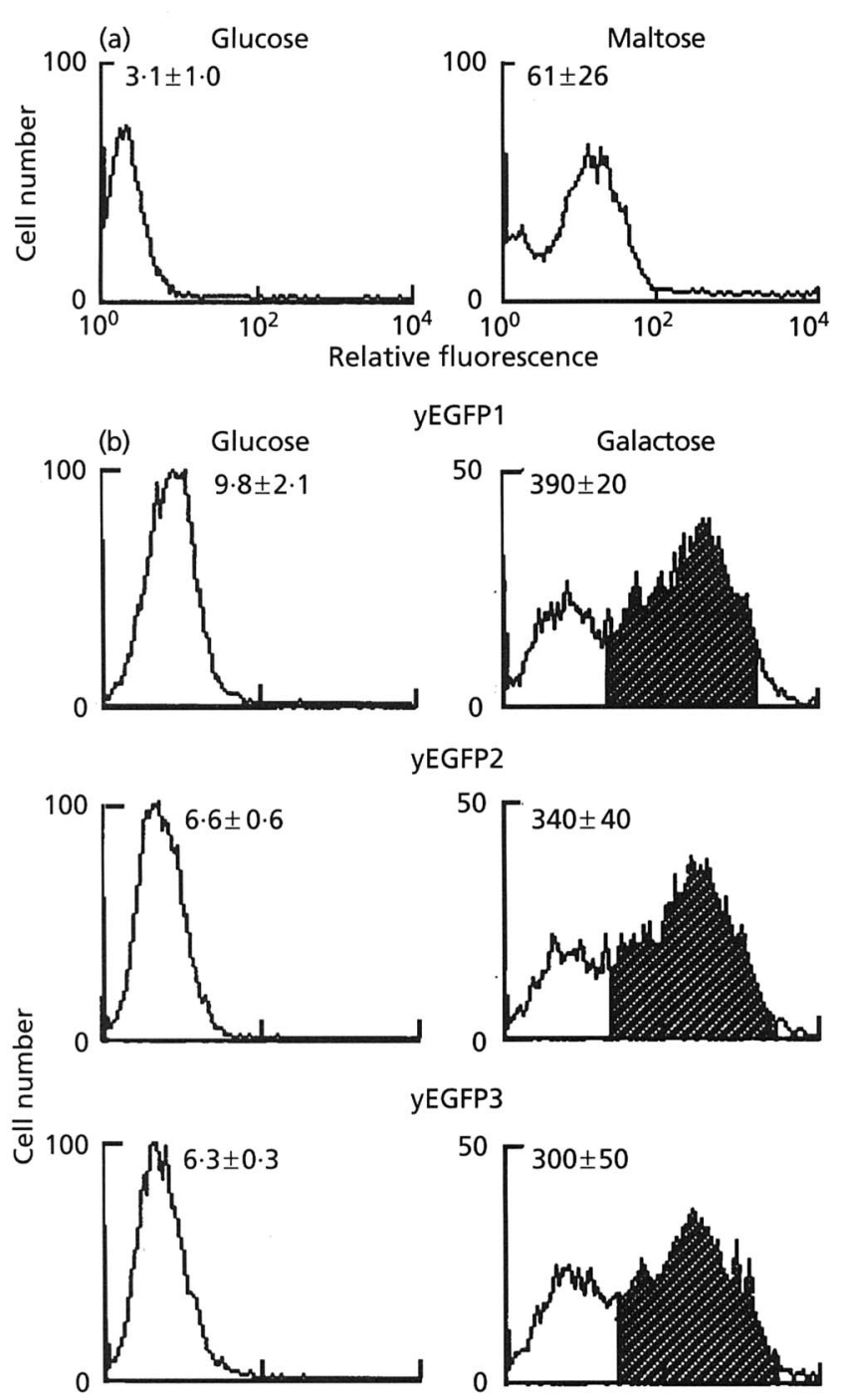

$50 \Gamma 340 \pm 40$

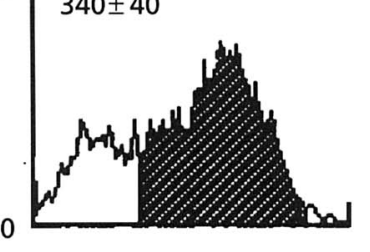

yEGFP3

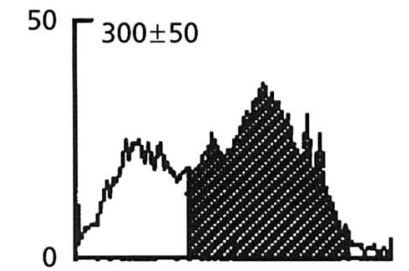

wt

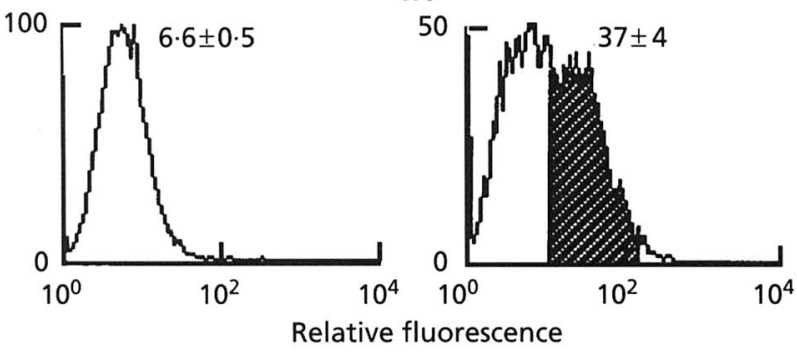

Fig. 5. (a) FACS analysis of C. albicans strains carrying the MAL2-GFP construct. The histograms shown are representative; the means and standard deviations shown are calculated from the mean fluorescence for three independent cultures. Transformants were grown overnight in synthetic media without uridine, and supplemented with either glucose or maltose $(2 \%, w / v)$. Each histogram represents a total of $2 \times 10^{4}$ events. The geometric mean fluorescence of each culture is shown in arbitrary units. (b) FACS analysis of S. cerevisiae strains transformed with pTS210 carrying either GFP ${ }_{w t}$ yEGFP1, yEGFP2 or yEGFP3. Transformants were grown overnight in synthetic media without uracil, and supplemented with either glucose or galactose $(2 \%, w / v)$. After growth in galactose, the populations of yeast cells were largely bimodal for fluorescence. For these populations, the mean fluorescence indicated in the figure was strains transformed with a plasmid carrying $\mathrm{GFP}_{\mathrm{wt}}$ expressed from the $A D H 1$ promoter. This demonstrates that the optimized yEGFP3 gene gives higher signals than $\mathrm{GFP}_{\mathrm{wt}}$ in $S$. cerevisiae. Codon-optimized versions of two other highly fluorescent mutants of GFP, mut 1 and mut2 (Cormack et al., 1996), were also tested. When expressed in S. cerevisiae from a GAL1,10 promoter, all three of the GFP mutants gave comparable results, paralleling their comparable fluorescence in E. coli. With this promoter, strains expressing the codonoptimized, fluorescence-enhanced GFPs were approximately 10 times more fluorescent than $\mathrm{GFP}_{\mathrm{wt}}$ expressed from the same promoter (Fig. 5).

\section{In vivo expression of yEGFP3}

Lastly, because GFP fluoresces in the absence of any added cofactors, theoretically it can be used as a marker inside live infected animals. We therefore tested whether C. albicans expressing yEGFP3 could be detected in tissue from infected animals. BALB $/ \mathrm{c}$ mice were injected intravenously with $1 \times 10^{6} \mathrm{CAI} 4$ cells transformed with the ADH1-yEGFP3 construct. After $24 \mathrm{~h}$, the mice were killed, and sections of the infected kidneys were examined. Numerous fluorescing C. albicans cells were visible in all sections examined. Fig. $6(c, d)$ shows a strongly fluorescent hyphal mass in the kidney of an infected mouse. Thus, C. albicans cells expressing yEGFP3 can be detected easily in infected tissue.

\section{DISCUSSION}

It is shown here that a codon-optimized and fluorescence-enhanced version of GFP can be used as an efficient reporter in S. cerevisiae and C. albicans. This optimized GFP is one of only a few reporters available for work in C. albicans. Development of such reporters has been complicated by the difficulty in expressing foreign genes in C. albicans, a failure that is generally assumed to result from the aberrant translation of CTG codons in this organism. However, when C. albicans was transformed with a GFP construct in which the CTG codon was changed to the preferred leucine codon TTG, GFP protein or fluorescence could not be detected, although GFP mRNA was present in these cells. This could be explained by the presence of a second problematic codon in C. albicans. Almost certainly, such a codon would be infrequently used, since the codonoptimized GFP is functional. Theoretically, this problematic codon could either be mistranslated, as in the case of the CTG codon, or alternatively it could be translated correctly but at a very low efficiency.

yEGFP3 is much more fluorescent than GFP $_{w t}$ in both $S$. cerevisiae and C. albicans. Part of this increase in

calculated using only the fluorescent population, indicated by the hatching. The mean fluorescence values calculated using the entire population of cells were $23 \pm 7,280 \pm 4,270 \pm 55$ and $212 \pm 43$ for $w$ and yEGFP1, 2 and 3 , respectively. 

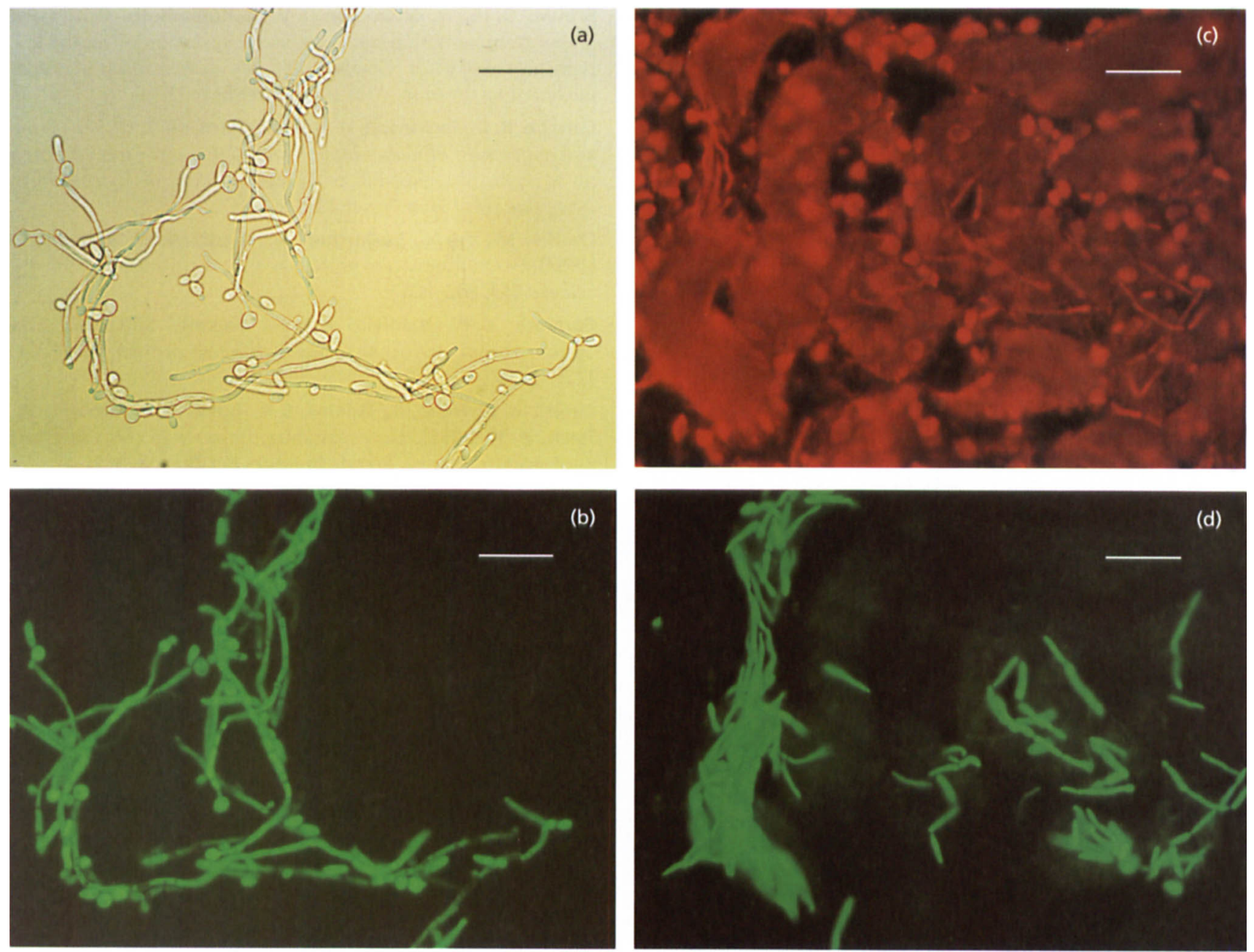

Fig. 6. (a) C. albicans expressing yEGFP3 visualized after growth overnight in YPD plus $10 \%$ foetal calf serum (Gibco-BRL). (b) The same field viewed by epifluorescence using $485 / 510 \mathrm{~nm}$ excitation/emission filters. (c) C. albicans expressing yEGFP3 visualized in murine kidney $24 \mathrm{~h}$ post-infection. A $10 \mu \mathrm{m}$ section of frozen kidney tissue stained with propidium iodide and viewed by epifluorescence using $540 / 605 \mathrm{~nm}$ excitation/emission filters is shown. (d) The same field viewed by epifluorescence using 485/510 nm excitation/emission filters. Bars, $10 \mu \mathrm{m}$.

fluorescence is almost certainly due to the increased translational efficiency of the codon-optimized gene. It seems likely, however, that the relatively high yEGFP3 mRNA levels also contribute to the elevated fluorescence. These elevated mRNA levels in S. cerevisiae and C. albicans may have been due to possible increases in the copy number of the ADH1-yEGFP3 plasmid. Alternatively, the codon optimization might have influenced the stability of the GFP mRNA either through direct effects upon mRNA stability determinants, or indirectly via an interplay between mRNA translation and degradation (Beelman \& Parker, 1995; Ross, 1995).

Apart from the GFP molecules described here, recently developed reporter systems exploit the $\beta$-galactosidase of $K$. lactis, and the luciferase of $R$. reniformis. GFP, $\beta$ galactosidase and luciferase all have certain advantages as reporters of transcription. The $\beta$-galactosidase and luciferase seem to be sensitive over a larger range than yEGFP3, and they are possibly more easy to quantify than GFP. Even expressing yEGFP3 from the fairly strong $A D H 1$ promoter, the fluorescence in C. albicans was not overwhelming, being 150 -fold above background. Hence, it seems likely that in general, $\beta$ galactosidase and luciferase will be more useful than yEGFP3 as reporters of transcription in vitro.

On the other hand, yEGFP3 has other important advantages. First, unlike $\beta$-galactosidase or luciferase, yEGFP3 can be monitored at the level of a single cell. Secondly, since GFP requires no cofactors, yEGFP3 can be used as a marker in applications where it is advantageous to maintain cell viability. Hence FACS sorting could be used to separate yeast cells on the basis of differential GFP expression levels, thereby permitting new types of genetic screens in C. albicans. In addition, as shown here, yEGFP3 can be used as a reporter in animal tissue, potentially allowing the dissection of transcriptional programmes that respond to the complex microenvironments of the host. Lastly, as a marker for 
protein localization, yEGFP3 is a uniquely powerful tool. As has been demonstrated in many other systems, fusions of GFP to endogenous proteins can be used to visualize the normal subcellular localization of those proteins. Therefore, yEGFP3 should be useful in the analysis of protein localization during growth and development in C. albicans, both in vivo and in vitro.

There remain some unresolved issues with GFP expression in C. albicans. It is possible that yEGFP1, which is approximately $30 \%$ more fluorescent than yEGFP3 in S. cerevisiae (Fig. 5), will also be more fluorescent in C. albicans. We have no estimate for the time lag between yEGFP3 protein production and fluorescence in $C$. albicans, a parameter that will be important for some studies of gene regulation. Furthermore, it is well known that the formation of the GFP chromophore requires oxygen and that the redox state of the cell can influence fluorescence (Heim et al., 1994). Hence it will be interesting to see whether yEGFP3 shows differential fluorescence in $C$. albicans under different growth conditions, or in different growth phases. These concerns notwithstanding, yEGFP3 should prove a powerful tool in the study of C. albicans cell biology and pathogenicity.

\section{ACKNOWLEDGEMENTS}

We are grateful to Raphael Valdivia for help with FACS analysis, to Rachel Green for help with oligonucleotide synthesis, to Sheila Black and Caroline Barelle for their help with the Northerns and Westerns, to David Bailey for his in silicio advice, and to David Holland and Phillip Trueman for their help with oligonucleotide synthesis and DNA sequencing. We thank Tim Stearns for providing vectors, and Rachel Green and Joan Mecsas for critical reading of the manuscript. B.P.C. was supported by a postdoctoral fellowship from the Helen Hay Whitney foundation, and by an unrestricted gift to S.F. from Praxis-Lederle Pharmaceuticals. G.B. was supported by a grant from Zeneca Pharmaceuticals, and A. J.P.B. was the recipient of a Research Fellowship from Aberdeen University.

\section{REFERENCES}

Bailey, D. A., Feldmann, P. J. F., Bovey, M., Gow, N. A. R. \& Brown, A. J. P. (1996). The Candida albicans HYR1 gene, which is activated in response to hyphal development, belongs to a gene family encoding yeast cell wall proteins. J Bacteriol 178, 5353-5360.

Beelman, C. A. \& Parker, R. (1995). Degradation of mRNA in eukaryotes. Cell 81, 179-183.

Bertram, G., Swoboda, R. K., Gow, N. A. R., Gooday, G. W. \& Brown, A. J. P. (1996). Structure and regulation of the Candida albicans $A D H 1$ gene encoding an immunogenic alcohol dehydrogenase. Yeast 12, 115-128.

Brown, A. J. P. (1994). RNA extraction and mRNA quantitation in Candida albicans. In Molecular Biology of Patbogenic Fungi: a Laboratory Manual, pp. 127-134. Edited by B. Maresca \& G. S. Kobayashi. New York: Telos Press.

Brown, A. J., Bertram, G., Feldmann, P. J., Peggie, M. W. \& Swoboda, R. K. (1991). Codon utilisation in the pathogenic yeast, Candida albicans. Nucleic Acids Res 19, 4298.
Brown, D. H., Jr, Slobodkin, I. V. \& Kumamoto, C. A. (1996). Stable transformation and regulated expression of an inducible reporter construct in Candida albicans using restriction enzymemediated integration. Mol Gen Genet 251, 75-80.

Cannon, R. D., Jenkinson, H. F. \& Shepherd, M. G. (1992). Cloning and expression of Candida albicans $A D E 2$ and proteinase genes on a replicative plasmid in C. albicans and in Saccharomyces cerevisiae. Mol Gen Genet 235, 453-457.

Chalfie, M., Tu, Y., Euskirchen, G., Ward, W. W. \& Prasher, D. (1994). Green fluorescent protein as a marker for gene expression. Science 263, 802-805.

Cormack, B. P., Valdivia, R. H. \& Falkow, S. (1996). FACS optimized mutants of the green fluorescent protein (GFP). Gene 173, 33-38.

Cubitt, A. B., Heim, R., Adams, S. R., Boyd, A. E., Gross, L. A. \& Tsien, R. Y. (1995). Understanding, improving and using green fluorescent proteins. Trends Biochem Sci 20, 448-455.

Cutler, J. E. (1991). Putative virulence factors of Candida albicans. Annu Rev Microbiol 45, 187-218.

Feinberg, A. P. \& Vogelstein, B. (1983). A technique for radiolabeling DNA restriction endonuclease fragments to high specific activity. Anal Biochem 132, 6-13.

Fonzi, W. A. \& Irwin, M. Y. (1993). Isogenic strain construction and gene mapping in Candida albicans. Genetics 134, 717-728.

Geber, A., Williamson, P. R., Rex, J. H., Sweeney, E. C. \& Bennett, J. E. (1992). Cloning and characterization of a Candida albicans maltase gene involved in sucrose utilization. J Bacteriol 174, 6992-6996.

Gietz, D., St Jean, A., Woods, R. A. \& Schiestl, R. H. (1992). Improved method for high efficiency transformation of intact yeast cells. Nucleic Acids Res 20, 1425.

Guthrie, C. \& Fink, G. R. (1991). Guide to Yeast Genetics and Molecular Biology. San Diego \& London: Academic Press.

Heim, R., Prasher, D. C. \& Tsien, R. Y. (1994). Wavelength mutations and posttranslational autoxidation of green fluorescent protein. Proc Natl Acad Sci USA 91, 12501-12504.

Hostetter, M. K., Lorenz, J. S., Preus, L. \& Kendrick, K. E. (1990). The $\mathrm{iC} 3 \mathrm{~b}$ receptor on Candida albicans: subcellular localization and modulation of receptor expression by glucose. J Infect Dis 161, 761-768.

Ito, H., Fukuda, Y., Murata, K. \& Kimura, A. (1983). Transformation of intact yeast cells treated with alkali cations. $J$ Bacteriol 153, 163-168.

Kurtz, M. B., Cortelyou, M. W. \& Kirsch, D. R. (1986), Integrative transformation of Candida albicans, using a cloned Candida ADE2 gene. Mol Cell Biol 6, 142-149.

Laemmli, U. K. (1970). Cleavage of structural proteins during the assembly of the head of bacteriophage T4. Nature 227, 680-685.

Leberer, E., Harcus, D., Broadbent, I. D., Clark, K. L., Dignard, D., Ziegelbauer, K., Schmit, A., Gow, N. A. R., Brown, A. J. P. \& Thomas, D. Y. (1996). Homologs of the Ste20p and Ste7p protein kinases are involved in hyphal formation of Candida albicans. Proc Natl Acad Sci USA 93, 13217-13222.

Leuker, C. E., Hahn, A. M. \& Ernst, J. F. (1992). $\beta$-Galactosidase of Kluyveromyces lactis (Lac4p) as reporter of gene expression in Candida albicans and C. tropicalis. Mol Gen Genet 235, 235-241.

Lindquist, S. (1981). Regulation of protein synthesis during heat shock. Nature 293, 311-314.

Lloyd, A. T. \& Sharp, P. M. (1992). Evolution of codon usage patterns: the extent and nature of divergence between Candida 
albicans and Saccharomyces cerevisiae. Nucleic Acids Res 20, 5289-5295.

Moore, P. A., Sagliocco, F. A., Wood, R. M. \& Brown, A. J. (1991). Yeast glycolytic mRNAs are differentially regulated. Mol Cell Biol 11, 5330-5337.

Morise, J. G., Shimomura, O., Johnson, F. H. \& Winant, J. (1974). Intermolecular energy transfer in the bioluminescent system of Aequorea. Biochemistry 13, 2656-2662.

Myers, K. K., Sypherd, P. S. \& Fonzi, W. A. (1995). Use of URA3 as a reporter of gene expression in C. albicans. Curr Genet 27, 243-248.

Odds, F. C. (1988). Candida and Candidosis, 2nd edn. London: Bailliere Tindall.

Odds, F. C. (1994). Candida species and virulence. ASM News 60 , 313-318.

Ohama, T., Suzuki, T., Mori, M., Osawa, S., Ueda, T., Watanabe, K. \& Nakase, T. (1993). Non-universal decoding of the leucine codon CUG in several Candida species. Nucleic Acids Res 21, 4039-4045.

Prasher, D. C., Eckenrode, V. K., Ward, W. W., Prendergast, F. G. \& Cormier, M. J. (1992). Primary structure of the Aequorea victoria green-fluorescent protein. Gene 111, 229-233.

Ross, J. (1995). mRNA stability in mammalian cells. Microbiol $\operatorname{Rev~59,~423-450.~}$

Sanger, F., Nicklen, S. \& Coulson, A. R. (1977). DNA sequencing with chain-terminating inhibitors. Proc Natl Acad Sci USA 74, 5463-5467.

Santos, M. A. \& Tuite, M. F. (1995). The CUG codon is decoded in vivo as serine and not leucine in Candida albicans. Nucleic Acids Res 23, 1481-1486.
Santos, M. A., el-Adlouni, C., Cox, A. D., Luz, J. M., Keith, G. \& Tuite, M. F. (1994). Transfer RNA profiling: a new method for the identification of pathogenic Candida species. Yeast 10, 625-636.

Scherer, S. \& Magee, P. T. (1990). Genetics of Candida albicans. Microbiol Rev 54, 226-241.

Sidorova, J. M., Mikesell, G. E. \& Breeden, L. L. (1995). Cell cycleregulated phosphorylation of Swi6 controls its nuclear localization. Mol Biol Cell 6, 1641-1658.

Srikantha, T., Klapach, A., Lorenz, W. W., Tsai, L. K., Laughlin, L. A., Gorman, J. A. \& Soll, D. R. (1996). The sea pansy Renilla reniformis luciferase serves as a sensitive bioluminescent reporter for differential gene expression in Candida albicans. $J$ Bacteriol 178, 121-129.

Thomas, B. J. \& Rothstein, R. (1989). Elevated recombination rates in transcriptionally active DNA. Cell 56, 619-630.

Wang, S. \& Hazelrigg, T. (1994). Implications for $b c d$ mRNA localization from spatial distribution of exu protein in Drosophila oogenesis. Nature 369, 400-403.

Ward, W. W., Cody, C. W., Hart, R. C. \& Cormier, M. J. (1980). Spectrophotometric identity of the energy-transfer chromophores in Renilla and Aequorea green fluorescent proteins. Photochem Photobiol 31, 611-615.

White, T. C., Andrews, L. E., Maltby, D. \& Agabian, N. (1995). The 'universal' leucine codon CTG in the secreted aspartyl proteinase 1 (SAP1) gene of Candida albicans encodes a serine in vivo. J Bacteriol 177, 2953-2955.

Received 15 August 1996; revised 23 October 1996; accepted 28 October 1996. 